\title{
MODELING AND THERMAL ANALYSIS OF HEAT SINK WITH SCALES ON FINS COOLED BY NATURAL CONVECTION
}

\author{
Vinay Pal \\ ${ }^{I}$ Senior Engineer, R\&D-Solid State Lighting, Moserbaer India Ltd, Gautambudh Nagar, UP, India
}

\begin{abstract}
Heat removal is often a significant endeavor in LED luminaries. A lower junction temperature of LED impacts efficiency, life, performance \& reliability. This work addresses thermal performance of few popular designing approaches on Fins of heat sink and it's correlation with junction temperature (also referred as soldering point temperature) of LEDs cooled by natural convection. A comparative thermal simulation results has been presented on basic rectangular fins, pin fins and trapezoidal scaled tapered fins using SolidWorks Thermal Simulation. It is observed that thermal mass, exposed surface area \& geometric placement of fins plays a key role in deciding performance of fins and Heat Sink. A high power LED array is used as uniform heat load of 65 watt. An optimized heat sink has typical functional dependencies on material, fin structure, ambient temperature of surrounding fluid, orientation with respect to gravity, color, texture and conductivity of interface layer used between LED and heat sink.
\end{abstract}

Keywords: LED, Heat Sink, Fin design, FEA, Thermal simulation, SolidWorks, Scales on fins

\section{INTRODUCTION}

A major share of electricity generated worldwide is consumed in lightening up homes, streets, parking and highways daily. With global consciousness to save electricity, we witnessed an era of CFLs as energy efficient alternative of conventional incandescent lights. However with CFLs, the important drawback is usage of hazardous chemicals such as lead and mercury. Previous decade saw induction of LEDs from laboratory to mass manufacturing. Initially the technology was viable for industrial lighting and sectors of high wattages as street lights and high mast lights. LED is now widely accepted in general purpose lighting due to its distinctive advantage of high energy efficiency and environmental friendly nature. In future LED lighting is inevitable owing to its huge savings in cost and quick return of investment.

Structurally LED is a p-n junction, in which holes recombine with electrons to radiate electromagnetic waves in visible spectrum along with substantial emission in IR region, generating unwanted heat in the chip. An increased junction temperature stimulates null radiative electron-hole recombination, which reduces lumen efficiency, popularly termed as efficacy in the industry. Although LEDs are quite efficient than CFLs \& incandescent lights, but still 65-75\% of electrical energy supplied is lost in form of heat losses. Key parameters such as performance, efficacy and reliability are inversely proportional to junction temperature. There are three ways by which junction temperature can be reduced: first is by limiting heat generation in chip, without compromising illumination, secondly by adopting thermal efficient heat sinks and thirdly by reducing thermal resistance of the system. In the former case, research is carrying out in many countries to reduce heat generation in package without degrading lumen output. It is also noticed that now LEDs are now approximately $25 \%$ efficient which used to be $20 \%$ few years ago. Sometimes while designing LED system, manufacturer specifies lumen output in terms of cold lumen or hot lumen. It is sometimes misleading while designing heat sink. Lumen output at $25^{\circ} \mathrm{C}$ junction temperature is termed as cold lumen while at operating junction temperature as hot lumen. To increase thermal efficiency of heat sinks, industrial designers are using CFD and FEA approaches to optimize heat sink; remove material where not required and add where required so that the design is cost effective and incorporate feedback of previous designs in subsequent designs. Here it becomes relevant to state that, mostly industries now use the term "case temperature", due to impractical measurement of junction temperature. It is simply the temperature of soldering pads upon which the LED package is mounted and is easily measured with thermal imaging camera, thermocouple. It is a function of junction temperature, internal thermal resistance and power drawn.

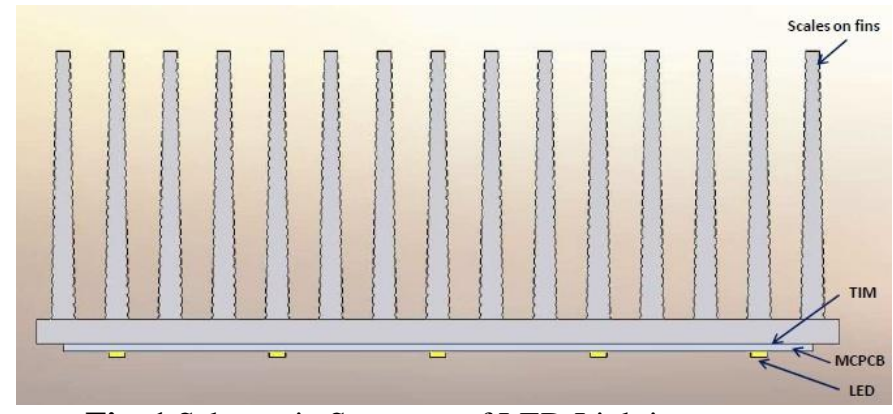

Fig. 1 Schematic Structure of LED Lighting system

$$
\mathrm{T}_{\mathrm{J}}=\mathrm{T}_{\mathrm{c}}+\left(\mathrm{R}_{\theta \mathrm{JC}} \times \mathrm{P}_{\mathrm{D}}\right)
$$

Where: $\mathrm{T}_{\mathrm{c}}=$ Case Temperature for the package $\left({ }^{\circ} \mathrm{C}\right)$ $\mathrm{R}_{\theta \mathrm{JC}}=$ Junction to Case Thermal Resistance $\left({ }^{\circ} \mathrm{C} / \mathrm{W}\right)$ $\mathrm{P}_{\mathrm{D}}=$ power dissipation in package $(\mathrm{W})$ 
There are many ways to reduce overall thermal resistance of the system and provide shortest possible path to dissipate heat out of system. Proper selection of thermal interface material (TIM) of higher conductivity thermal grease or thermal tape, driving LED at lower current to reduce losses through droop effect, active cooling, phase change cooling are some of the options.

This work is dedicated to the study of different fin designs and their performances in natural convection using FEA approach. Rectangular fins are the most basic and popular design due to its low manufacturing cost and satisfactory performance in low wattage ranges. Much popular pin fins type design is known for its best thermal performance in class for forced convection. It is studied for its performance in natural convection environment. However manufacturing cost of pin fins is still on a higher side due to increased cost on CNC operations to produce precise pins compared to all fin designs studied. Scaled fins have minute indentations on fins running along its length. These minor curves increase net surface area of fins to make them quite efficient. Extrusion of such fins is simple and economical.

\section{MODELING AND MEASUREMENTS}

The paper designs heat Sink with rectangular fins, pin fins and scaled fins is done in SolidWorks 2014 Premium. A flat platform of $150 \times 150 \times 5 \mathrm{~mm}$ is common in all designs. Fin height for all models is $55 \mathrm{~mm}$. Material for fins and heat sink considered for all designs is, Aluminum 6063, which is preferred for its wide application due to its high thermal conductivity of around $152 \mathrm{~W} /(\mathrm{m} . \mathrm{K})$ and suitability for extrusion and machining operations. Metal core printed circuit board (MCPCB) is used to mount power LEDs in array of $5 \mathrm{X}$ 5 operated at $1 \mathrm{~W}$ each. Dimensions of MCPCB are 140 X 140 X $1.5 \mathrm{~mm}$.

\subsection{Rectangular Fins}

Figure 2, shows a basic and regular rectangular fin heat sink is designed with fins running through the length of platform and height at $55 \mathrm{~mm}$; fin thickness is $2.5 \mathrm{~mm}$ \& pitch is 10 $\mathrm{mm}$. Net surface area of heat sink is $299624 \mathrm{~mm}^{2}$. The shape is easily manufactured by extrusion.

\subsection{Pin Fins}

Figure 3 shows a basic and regular rectangular fin heat sink is designed with diameter of pins equals $10 \mathrm{~mm}$ with a height of $55 \mathrm{~mm}$; Pitch is $20 \mathrm{~mm}$. Net surface area of heat sink is $132665.92 \mathrm{~mm}^{2}$.

\subsection{Tapered Scaled Fins}

Figure 4 shows trapezoidal shape fins with a draft angle of $1^{\circ}$ on either side. These runs along the width of platform with a height of $55 \mathrm{~mm}$; fin thickness at the bottom is $4.5 \mathrm{~mm}$ and $2.58 \mathrm{~mm}$ at top \& pitch is $10 \mathrm{~mm}$. Net surface area of heat sink is $317022.35 \mathrm{~mm}^{2}$. The shape can be easily manufactured by extrusion process.

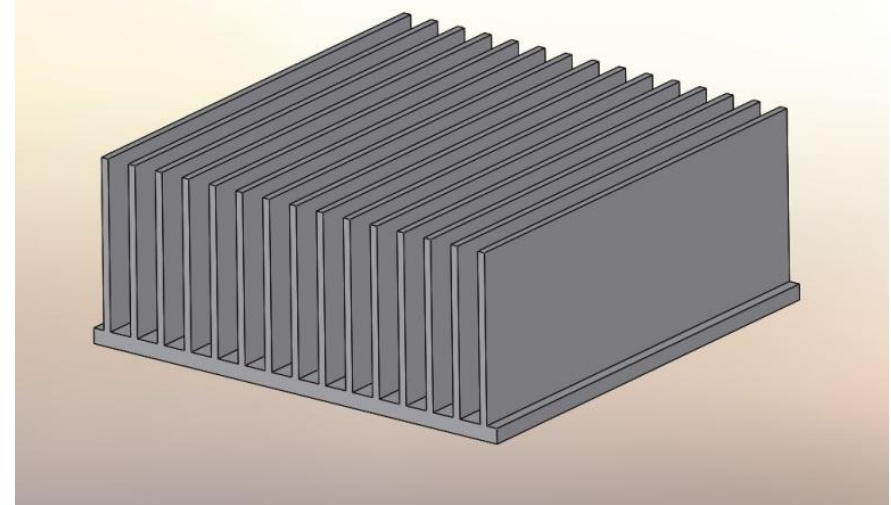

Fig. 2 Rectangular fin heat sink

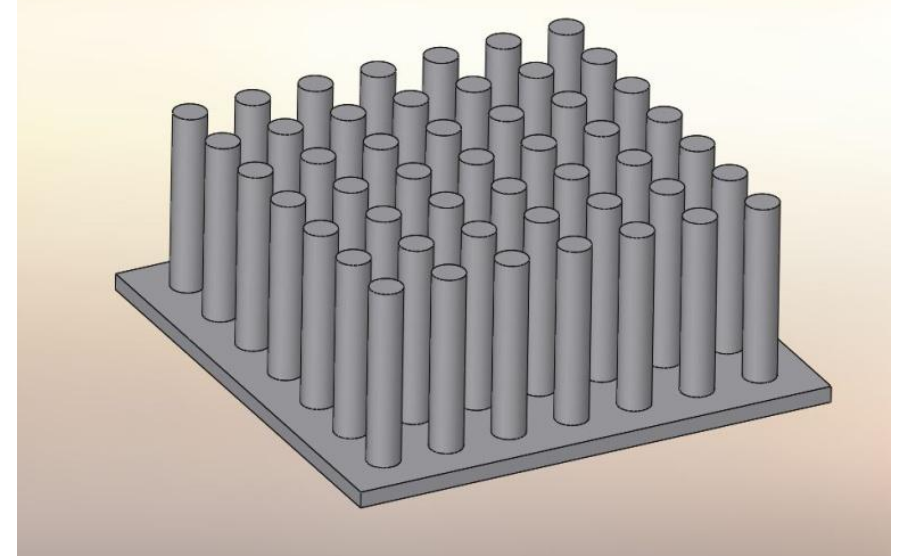

Fig. 3 Pin fin heat sink

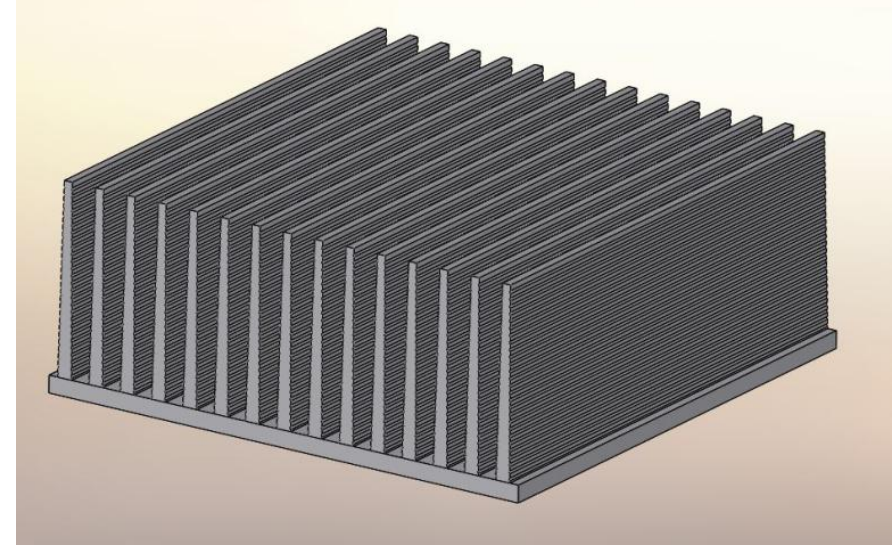

Fig. 4 Trapezoidal scaled fin heat sink

\section{THERMAL MODELING AND SIMULATION}

Finite Element Analysis (FEA) approach is used to do thermal modeling and analysis of all models with SolidWorks Simulation Premium 2014. Tetrahedral element is used in meshing. DIRECT SPARSE algorithm is used by solver. The methodology is known for high accuracy for conductivity gradient and also incorporates fluid mechanics. The approach taken in this paper is to compare Case temperature of LED array of all designs having similar volume. The paper follows boundary conditions as, ambient temperature is assumed at $25^{\circ} \mathrm{C}$. Air convection coefficient assumed at $10 \mathrm{~W} /\left(\mathrm{m}^{2} . \mathrm{K}\right)$. Heat transfer through radiation from fins surface is controlled 
by emissivity value of material used which is assumed at 0.7 , thermal conductivity of thermal interface material (TIM) usually thermal grease or thermal tape is approx $3 \mathrm{~W} / \mathrm{m} . \mathrm{k}$. Power LED package measuring $3 \times 3 \times 0.8 \mathrm{~mm}$, is driven at $1 \mathrm{~W}$ and since $75 \%$ of power transformed into heat and rest into lumen output, the heat generated by one LED chip is:

$$
\begin{gathered}
\mathrm{q}=\mathrm{P}_{\mathrm{d}} / \mathrm{V}=1 \times 75 \times 10^{9} /(3 \times 3 \times 0.8)=10.41 \times 10^{9} \\
\mathrm{~W} /\left(\mathrm{m}^{3} . \mathrm{k}\right)
\end{gathered}
$$

Where, $\mathrm{q}$ is heat generated, $\mathrm{P}_{\mathrm{d}}$ is the power drawn and $\mathrm{V}$ is volume of LED chip.

\section{RESULTS AND DISCUSSION}

It can be clearly be inferred that when heat sink is cooled by natural convection, effectiveness of heat sink is proportional to its surface area. Of all designs studied, trapezoidal fin design outperformed other two designs. Figure 5, 6, 7 shows the thermal simulation results of 3 designs. The maximum case temperature was observed with pin fin heat sink design measuring $\mathrm{T}_{\mathrm{c}}=51.413{ }^{\circ} \mathrm{C}$ and weighting $875.24 \mathrm{gms}$. Of all designs trapezoidal fin design, $1429.59 \mathrm{gm}$ is also the heaviest of 3 designs. Table 1 summarizes net surface area of each fin design studied and corresponding case temperatures achieved.

Table 1 Surface area and Case Temperature of different fin design Heat Sink

\begin{tabular}{|l|l|l|}
\hline Design type & $\begin{array}{l}\text { Surface Area } \\
\left(\mathrm{mm}^{2}\right)\end{array}$ & $\begin{array}{l}\text { Case Temperature } \\
\left({ }^{\circ} \mathrm{C}\right)\end{array}$ \\
\hline Rectangular Fin & 299625 & 46.482 \\
\hline Pin type & 132665.92 & 51.413 \\
\hline Trapezoidal fin & 317022.35 & 44.862 \\
\hline
\end{tabular}

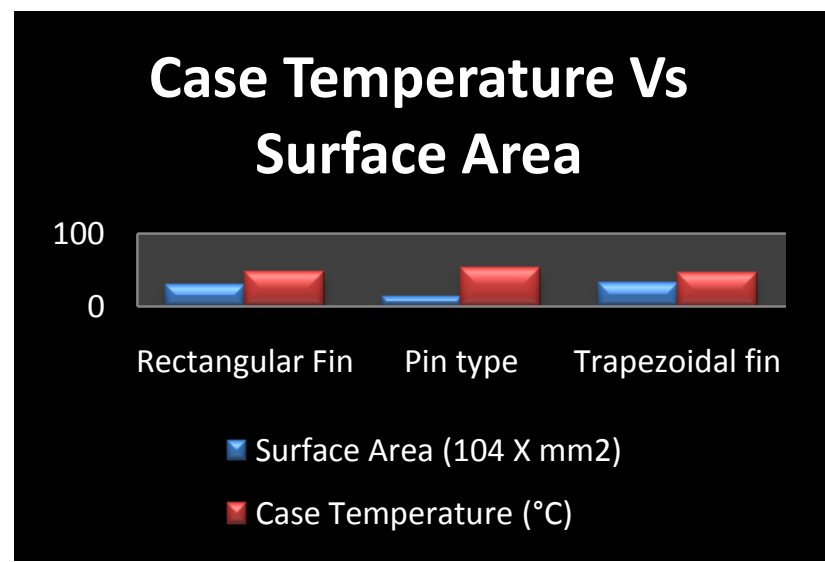

Fig 5 Comparison of Case Temperature Vs Surface Area

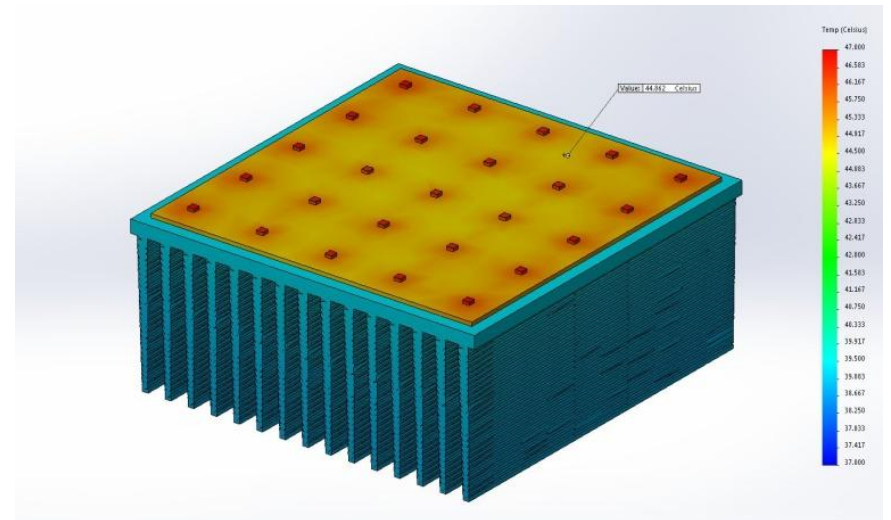

Fig 6 Temperature distribution of trapezoidal scaled fin Heat Sink

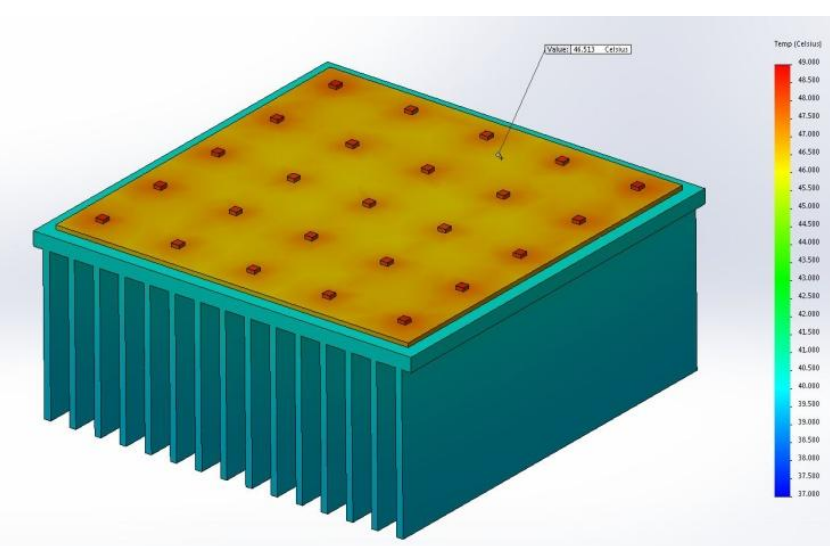

Fig 7 Temperature distribution of rectangular fin Heat Sink

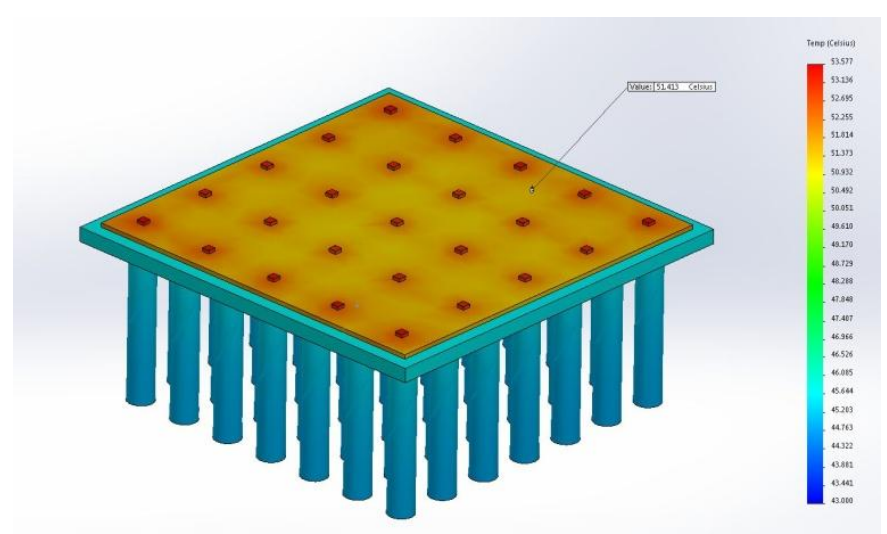

Fig 8 Temperature distribution of pin fin Heat Sink

\section{CONCLUSIONS}

The paper presents thermal analysis and simulation of rectangular fin, pin fin and trapezoidal scaled fins of heat sink for a high wattage LED system cooled by natural convection. A 5 X 5 LED array of total 25 watt is designed as power source; total heat load is 18.75 watt. The three types of heat sink are compared in similar conditions. It is found that of all designs simulated, heat sink with trapezoidal scaled fins performed best with a case temperature of $44.862^{\circ} \mathrm{C}$. It can also be inferred that the pin fin heat sink design is not suitable for applications involving natural cooling. 


\section{NOMENCLATURE}

$\mathrm{W}=$ Wattage

$\mathrm{T}_{\mathrm{J}}=$ Junction Temperature, ${ }^{\circ} \mathrm{C}$

$\mathrm{T}_{\mathrm{c}}=$ Case Temperature, ${ }^{\circ} \mathrm{C}$

$\mathrm{R}_{\theta \mathrm{JC}}=$ Thermal Resistance, ${ }^{\circ} \mathrm{C} / \mathrm{W}$

$\mathrm{P}_{\mathrm{D}}=$ Power drawn, $\mathrm{W}$

$\mathrm{q}=$ Heat Generated

$\mathrm{V}=$ Volume, $\mathrm{m}^{3}$

\section{ACKNOWLEDGMENTS}

It is a great pleasure for me to acknowledge Moserbaer India ltd for its support.

\section{REFERENCES}

[1] J.richard culham, M. michael Yovanovich, Seri Lee, IEEE transactions oncomponents, packaging, and manufacturing technology-Part A, Vol 18, Sept 1995

[2] Hou Fengze, Yang Daoguo, ZhangGuoqi. Thermal analysis of LED lighting systemwith different finheat sinks. Journal of Semiconductors vol 32, Jan 2011

[3] R. Sam sukumar, G.Sriharsha, S.Bala Arun, P.Dilip Kumar, Ch. Sanyasi Naidu. Modelling and analysis of heat sink with rectamgular fins with through holes. International journal of Engineering researchand application (IJERA). Vol 3, Issue 2. March-April 2013.

[4] Christopher L. Chapman, Seri Lee, Bill L. Schmidt. Thermal performance of an elliptical pin fin heat sink, $10^{\text {th }}$ IEEE SEMI-THERM.

[5] S. Shanmugam, D.Mutharasu, O.Zeng Yin. Performance of Light emitting diode on surface machined heat sink. International journal of PowerElectronics and Drive system(IJPEDS), Vol 2, No .4 Dec, 2012 